\title{
Determination of Prices for Services in Online Marketing in Vkontakte Social Network
}

\author{
Plotnikov A.V. \\ Management \& Marketing Department, Perm National Research Polytechnic University, Perm, Russia \\ *Corresponding author. Email: plotnikov-av@mail.ru
}

\begin{abstract}
The paper reveals the issues of the Internet presence of companies in the market as an inevitable part of marketing communication at the present stage of economic and technological development. We consider ecommerce, its features and prospects in social networks. The practical part of the work determines prices for services in the field of contextual advertising and social network marketing. The selection of services displayed on the 'VK Products' data mart is $N=19765$. Products were collected from 3127 communities; the topics of the communities correspond to social media marketing and contextual advertising. Prediction of "incorrect" price values of 'goods' is determined using linear regression, Random forest and k-neighbors method.
\end{abstract}

Keywords: social network, digital economy, two-side market, information technologies

\section{INTRODUCTION}

The field of Social media marketing (SMM) is one of the most important areas of Internet marketing and digital economy. Cost of advertising space on sites per time, per number of impressions or clicks on advertising is one of the main elements of marketing costs. Ensuring the effective launch of advertising, delivering it to the target audience and determining the exact targeting has always been a problem for Internet marketers. One approach is to minimize losses in online advertising by more accurately targeting advertising to special segments of consumers in the market using predefined criteria and attributes. Due to improvements in the ability to collect and process data, companies have better information about consumers, their preferences and their habits. The second change is the fragmentation of existing media and the advent of online media.

The research is devoted to studying the online environment in the social network VK, which has turned into a market offering consumers the opportunity to make purchases of goods and services around the world, regardless of belonging to a certain geographical position, as well as make secure electronic transactions without leaving home. The Internet has also increased the distribution of channels and ways to reach consumers through online social media advertising for retailers, service providers and manufacturers. Social networks and a number of modern technologies have also evolved to provide retailers with the services of suppliers and manufacturers through ways to attract consumers to their traditional sources of goods. Retailers can get marketing information about consumers to help them identify potential demand.
The online advertising market is experiencing continuous and significant growth every year. More and more companies in the modern world devote a significant part of their marketing budget to online communication, in comparison with traditional methods. So, it would be useful for a marketing decision-maker to understand the trends regarding the various types of targeted advertising options available, as well as to know the new trends in the field of marketing communications. Some issues of marketing communications are considered in the works by Duncan T. R. [11], Schultz D. E. [13], Daymon C. [10], Fill C. [12], Smith P. R. [14] and have already become classics. Marketing communications are actions in the form of messages that are aimed at both the internal and external target audience, with the aim of influencing the behavior of people regarding a product / service.

The modern market of goods and services is oversaturated with a huge variety of offers. In such conditions, companies strive to stand out among competitors, surprise consumers, offer them the best conditions, both material and communicative. The sale of goods requires the development of marketing communications, regardless of the size of the manufacturer and his place in the market. The development of information technology provides companies with the opportunity to use new solutions to achieve their economic goals. It is the Internet today that is becoming the main source of the relationship between seller and buyer, provides comprehensive information about a product or service. Consider the concept and main points of e-commerce, which enjoys the attention of an increasing number of researchers.

The Internet is fully integrated into all areas of our lives. Online communication is replacing old ways of connecting 
users and companies. It is on the Internet today that we are trying to look for all the necessary information about a seller, manufacturing company or product. The transition of an increasing number of users to the Network, their growing trust in the information received in the virtual world, forces companies to develop their presence on the Internet, Valko D.V. [2] concludes in his work. The researchers have proposed a new concept of "ecommerce", which characterizes the ongoing processes. It refers to the sphere of the digital economy, including trade and financial transactions occurring through computer networks. E-commerce also includes ongoing business processes launched by these transactions. Olshansky A.V. [6] in his work highlights the benefits for the buyer after the introduction of e-commerce. First of all, these are convenient digital catalogs for finding the necessary goods, well-functioning logistics and a delivery system to stores, as well as low prices compared to offline sites (due to the lack of costs for renting large halls and labor).

An important part of e-commerce is marketing communication, according to Vaisman V.B. and Yasyreva A.A. [1]. The promotion of goods by a company is not least due to continuous communication with customers, which is the most important means of attracting the target audience. The primary task is to correctly identify the target audience, which can minimize marketing costs and at the same time increase its effectiveness.

A modern Internet user, thinking about purchasing goods, first of all starts looking for information in social networks, profile blogs and forums. Social networks today are a new highly effective tool to stimulate the sale of goods and services. For this, the so-called promotion in social networks is used. In this work, we put special emphasis on the SMM sphere, which combines information technology and humanitarian knowledge about people, which represents a point impact on the audience, the selection of the most effective ways of communication at the site where the target audience is represented. To select the target audience in a social network, it is necessary to select from a variety of user profiles those that would have the same value of the desired attribute. In the work by Shompolov I.G. and Sidorets R.A. [8] the task is set of finding a certain subset of users by means of their own software. Solutions based on the developed program can be effectively applied in electronic commerce and social media marketing. Zlobina N.V. and Zavrazhina K.V. [4] in their work continue the theme of social media marketing. They consider the most relevant ways to develop this industry today. These include combining offline and online, improving engagement, situational marketing, and more. The work reveals a trend of rapid development of social networks. The demand for video content is especially great, that is why online marketers are actively using viral advertising campaigns. According to the results of the study, an unequivocal conclusion is made about increasing customer loyalty to online stores.

A significant advantage of transactions on social networks is the visualization between participants through personal profiles. In addition, reviews of this seller or store are the most important trigger for transactions on the Web. Each buyer on the Internet first of all looks at reviews about a product or a seller, the interface of the site and even prices below market are often of secondary importance. Various marketing areas are being implemented: the development of groups of various stores, viral marketing, contextual advertising, banner advertising and others. At the same time, the main reason hampering the development of digital marketing is the fear of becoming a victim of scammers.

Intangible resources are important in electronic commerce. It is these resources associated with the interaction of managers and customers that play a significant role in the economic activities of companies, as Evstratova Yu.A., Nikishin A.F. and Shipilova S.S. believe [3]. These include business reputation, customer loyalty, and the availability of one's own base of regular customers. Users are sure to analyze the activities of the store when planning their purchases.

For information technology companies, standard economic rules and laws apply. In market economy, in order to make a profit in the long run, an organization must be sustainable and competitive. One of the most important factors in the success of a product or service is the brand strength. Companies that adhere to the principles of value added communities gain the greatest market power.

\section{FUNCTION IN THE VK GOODS SOCIAL NETWORK}

For the convenience of companies working in the field of electronic commerce in social networks, there is a special section VKontakte Goods offering an opportunity to set up a showcase with goods and services in the company's community. This function will be useful not only for existing companies, but also for beginner online stores, which can easily manage a page on social networks without spending money on creating a personal web page [7]. The system is very simple: cards with goods are added in the community of the store, where one can insert photos, prices and descriptions. All products can be sorted into collections by category for the convenience of users. Not so long ago, a service with VKontakte Goods became available for private users of the social network [5]. In this work, we collected information about 'goods' (IT services) on the VKontakte social network and we are going to determine anomalous prices (indicated as less than 10 rubles).

For maximum automation of the store's work with goods, one can use the interface offered to business owners on a social network. The VKontakte API offers information from the database of the entire social network through user requests to a specialized server. Using a special form, the company owner needs to register his own application. It can be of various types, either work directly on the main page on the network, or run on a mobile client or external site. Then add products to this application using the 
appropriate parameters and an image to them. [9] Users interested in products will install this application, after which their friends will begin to join you, thereby increasing the target audience. For maximum user convenience, platforms of popular services for business work on the social network, for example, 1C-Bitrix and others. These applications for administration and control over the work of employees are very suitable for business at any level.

\section{RESEARCH METHODS}

In the study, we have collected information about 'goods' (IT services) on the VKontakte social network and we forecast abnormal prices using various methods. To do this, we carry out the following procedures. We determine the procedure for tokenizing the text field and check its operation. We tokenize the "Name" field and check the result. We define a class for counting the "average" vector of words included in the text field (using word2vec). We create the Word2Vec model ( $\mathrm{N}=19765 \mathrm{VK}$ products). Products have been collected from 3127 communities. Community topics are consistent with social media marketing and contextual advertising. We create a dictionary of words and their corresponding vectors. We accumulate averaged vectors in the name_means array that correspond to the names of groups and, for the convenience of manipulation, translate the array into a data frame. Preparing the column with prices (price, P) in the main data frame: we translate the values to the number format and create a column 'is_correct' in which 1 will be a sign of the correct price.

Conditions for observing the correct price $10<\mathrm{P}<100,000$ rubles. The model is based on the following premise: a price of less than 10 rubles does not reflect an objective assessment of services in monetary terms and is rather formal in filling in the field 'price' as compliance with VK requirements for creating a product card. Prediction of price values 'of goods' is determined using linear regression, Random forest, using the k-neighbors method. The accuracy of the model will be measured by the averaged over the cross-validation folds value of the standard deviation $(\sigma)$ for the logarithmic value of the price.

\section{RESEARCH RESULTS \& DISCUSSIONS}

We divide the data into training - train, and those we will predict - test, and see how the price value is distributed in the training part (see Fig. 1). I.e., the first graph is the distribution of prices among those groups that did not have abnormal prices.

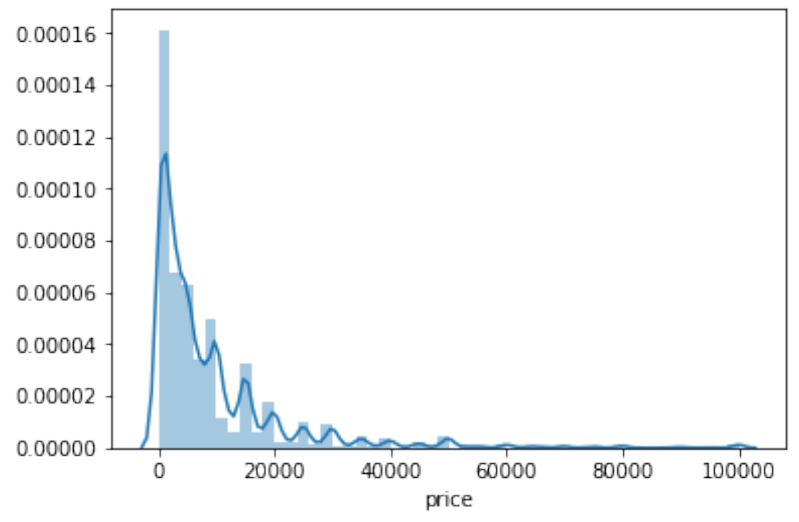

Figure 1 Distribution of prices for 'products' on the VK social network

Obviously, the values are extremely asymmetric with a strongly stretched right tail. For the stable operation of the models, we logarithm them and look at the resulting distribution.

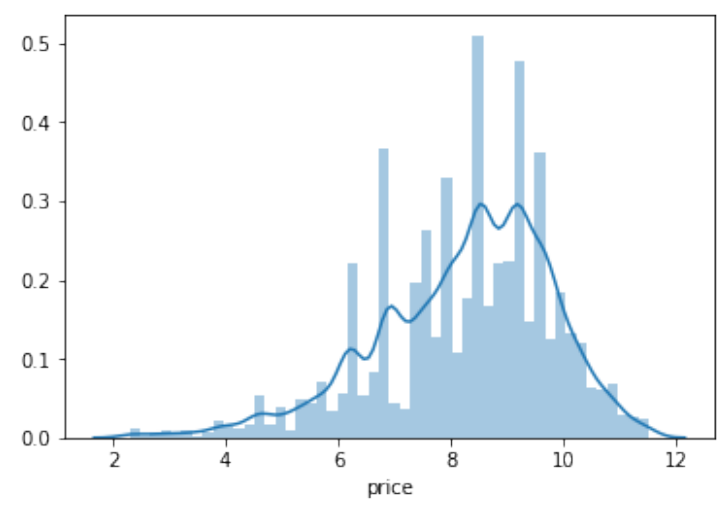

Figure 2 Normalized Price

We finally prepare the datasets for training and make sure of the correctness $(17192,2573)$

The accuracy of the model will be measured by the averaged over cross-validation folds value of the standard deviation $(\sigma)$ for the logarithmic value of the price. We define the function of calculating the standard deviation for cross-validation. Let's create the first model: linear regression with 11- and 12-regularization. We train it and determine the standard deviation $\sigma=$ 1.3545585232840933 .

The second model is Random forest. We will train it and determine the standard deviation,

$\sigma=1.3842048200259727$.

And the third model, the k-neighbors regressor, where the standard deviation

$\sigma=1.3669006385991367$.

The linear model showed the greatest accuracy. To be sure, we visualize its results (blue color) and the next most accurate model in a random sample (Fig. 3) 
community administrators set the wrong prices. This is caused by the fact that users of the social network set prices to formalize the filling of the necessary fields to create a product card. In the practical part of the work, we predicted prices for IT services by three methods, where the linear regression method showed the best result.

\section{ACKNOWLEDGMENT}

The study was supported by the grant from the President of the Russian Federation for state support for research by young Russian scientists - Candidates of Sciences (project MK698.2019.6).

We stop the choice on a linear model, calculate its price forecast for VK groups with incorrect values and transfer it from the logarithmic representation to a linear one. We replace in the initial sample the incorrect prices predicted by the model. We visualize the resulting column with the price in the original sample and make sure of the visual similarity with the distribution of prices on the "correct" data. (Fig. 4)

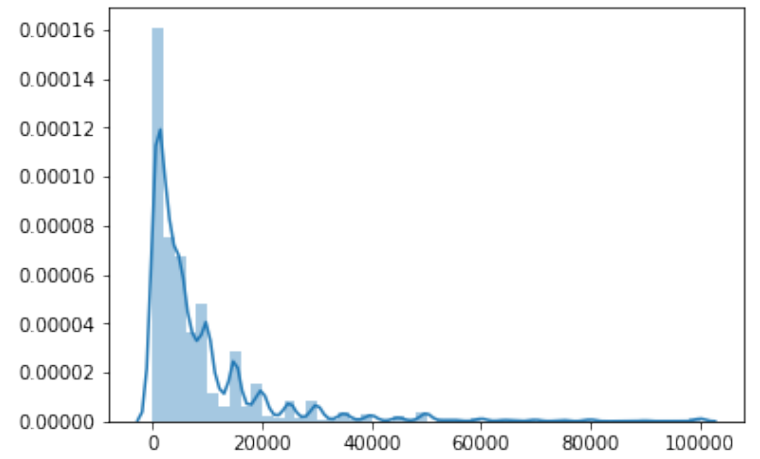

Figure 4 Sampling price distribution after replacing abnormal prices with predicted ones

Fig. 4 is a graph of the distribution of prices over the entire sample, after we have replaced the anomalous prices with the predicted ones. That fig. 4 is similar to fig. 1 shows generally the adequacy of predicted prices.

\section{CONCLUSION}

E-commerce already occupies a significant part of the market of goods and services. In the VKontakte social network the number of users of the new segment of the economy will only increase. The development of the information and communication sphere will relieve users of fears over the security of their data and money when paying for purchases on VKontakte using the money transfer function. Thus, the VKontakte social network today is one of the leading platforms, actively developing this area of activity on its own platform, providing the necessary resources and services to owners of online stores. When registering commodity cards on VKontakte, we observe the presence of price anomalies when

\section{REFERENCES}

[1] T. R. Duncan, S. E. Everett, Client perceptions of integrated marketing communications. J. Advertising Res., Vol. 33( 3) (1993) 30-40.

[2] D. E. Schultz, Integrated marketing communications, J. Promotion Mgmt., Vol. 1(1) (1992) 99-104.

[3] Daymon C., I. Holloway, Qualitative research methods in public relations and marketing communications. Routledge, 2010.

[4] C. Fill, Marketing communications: engagements, strategies and practice, Pearson Education, 2005, 952 p.

[5] P. R. Smith, Z. Zook, Marketing communications: integrating offline and online with social media, Kogan Page Ltd., 2011, 504 p.

[6] D. V. Valko, Internet presence as a conceptual basis of modern marketing. Bulletin of SMUS74, 1(1) (2013) 59-63.

[7] A.V. Olshansky, The use of e-commerce in modern conditions of development of domestic companies, Scientific Result. Technology Business and Service, 1(2014) 80-88.

[8] V.B. Vaysman, A.A. Yasyreva, Marketing communications for small business, Bulletin of PNRPU, Socio-economic sciences, 4 (2018) 275-284.

[9] I.G. Shompolov, R.A. Sidorets, Bypassing the social graph to identify people on social networks that have a common value of an arbitrary attribute with a given selection of users, Problems of Science, 26 (68) (2016) 5-8. 
[10] N.V. Zlobina, K.V. Zavrazhina,Social Media Marketing: Current Trends and Prospects, Sci.Tech. J. of St. Petersburg State Polytechnic University, Economic sciences, 6(233). (2015) 166-172.

[11]Yu.A. Evstratova, A.F. Nikishin, S.S. Shipilova, The role of intangible resources in electronic commerce, Innovation science, 7-1(2015) 104-107.

[12]Products VKontakte [Electronic resource] - access mode: https://vk.com/dev/goods

[13]E. Iova, Products VKontakte: how to make a showcase without leaving the social network? [Electronic resource] - access mode: https://1ps.ru/blog/ smm-i-smo/2017/tovaryi-vkontakte-kak-oformitvitrinu-ne-vyixodya-iz-soczialnoj-seti/

[14]API for goods [Electronic resource] - access mode: https://vk.com/dev/goods_docs 